\title{
IMPORTANCE OF LIGHT INTENSITY SELECTION IN THE SURFACE TOPOGRAPHY MEASUREMENTS USING OPTICAL PROFILOMETER
}

\author{
ZNACZENIE DOBORU NATEZŻENIA OŚWIETLENIA \\ W POMIARACH CHROPOWATOŚCI Z WYKORZYSTANIEM \\ PROFILOMETRU OPTYCZNEGO
}

\begin{abstract}
Andrzej DZIERWA ${ }^{1}$
Abstract: Several isotropic and anisotropic surface topographies were analysed. Surface measurements were made using white light interferometer Talysurf CCI Lite, version 2.8.2.95. All surfaces were measured with different light intensity. Light intensity was changed in the range 10\%-90\% every time at 5\%. After measurement each surface was levelled and nonmeasured points were filled up. Parameters from ISO 25178 group and parameters from the $S k$ family were calculated. Parameters were calculated using the software Talymap Gold, version 6.0. Influence of light intensity on the change of surface topography parameters was analysed. Keywords: surface topography, light intensity, optical profilometer, surface roughness

Streszczenie: W pracy badano wpływ doboru natężenia oświetlenia na wyniki pomiarów parametrów chropowatości, jak również wpływ tegoż natężenia na ilość punktów niezmierzonych z wykorzystaniem interferometru światła białego Talysurf CCI light. Badaniu poddano zarówno próbki anizotropowe (szlifowane), jak i izotropowe (kulowane). Natężenie oświetlenia zmieniano w zakresie od 10 do $90 \%$ każdorazowo co 5\%. Określono wpływ zmiany natężenia oświetlenia na jakość pomiaru oraz na zmianę wartości parametrów chropowatości. Słowa kluczowe: topografia powierzchni, natężenie oświetlenia, profilometr optyczny, chropowatość powierzchni
\end{abstract}

\section{INTRODUCTION}

Every surface, even though it may appear smooth to the human eye, has some form of texture structure that takes the form of a series of peaks and valleys. Examination under a magnifying instrument will reveal this complex structure of peaks and valleys that vary in height and spacing and make up a surfaces texture. Examining this texture has a very practical significance. Surface texture has properties that are a result of the way the surface was produced

\footnotetext{
${ }^{1}$ Rzeszow University of Technology, Department of Manufacturing Process and Production Engineering
} 
(e.g. cutting tools produce uniform spacing with defined directions whilst grinding produces random spacing) as well as other factors such as crystal structure and paint on the surface [2]. Surface texture plays a vital role in the functionality of a component. It is estimated that surface effects cause $10 \%$ of manufactured parts to fail and can contribute significantly to an advanced nation's GDP. In the last century, surface texture was primarily measured by a method that involved tracing a contacting stylus across the surface and measuring the vertical motion of the stylus as it traversed the surface features. In most cases only a single line, or surface profile, was measured and this gave rise to enough information to control production, but was limited to identifying process change [9].

Over the past three decades there has been an increased need to relate surface texture to surface function and, whilst a profile measurement may give some functional information about a surface, to really determine functional information, a three dimensional (3D), or areal, measurement of the surface is necessary. Control of the areal nature of a surface allows a manufacturer to alter the way a surface interacts with its surroundings. By controlling the areal nature of a surface optical, tribological, biological, aerodynamic and many other properties can be altered $[3,4,8,10]$. The measurement of areal surface texture has a number of benefits over profile measurement [1]. Areal measurements give a more realistic representation of the whole surface and have more statistical significance. There is also less chance that significant features will be missed by an areal method and the manufacturer, therefore, gains a better visual record of the overall structure of the surface. The need for areal surface texture measurements resulted in stylus instruments that could measure over an area (a series of usually parallel profiles) and optical techniques. Optical instruments either scan a beam over the surface akin to stylus instruments, or take an areal measurement by making use of the finite field of view of a microscope objective. There are currently many commercial instruments that can measure areal surface texture, both stylus and optical.

In 2002, ISO technical committee 213 formed a working group (WG) 16 to address standardisation of areal surface texture measurement methods. WG 16 is developing a number of draft standards encompassing definitions of terms and parameters, calibration methods, file formats and characteristics of instruments. Several of these standards have been published and a number are at various stages in the review and approval process. The plan is to have the profile standards as a sub-set of the areal standards (with appropriate re-numbering). Hence, the profile standards will be re-published after the areal standards (with some omissions, ambiguities and errors corrected) under a new numbering scheme that is consistent with that of the areal standards. All the areal standards are part of ISO 25178, which will consist of at least the following parts, under the general title Geometrical product specification (GPS) - surface texture: areal [9]:

- Part 1: Areal surface texture drawing indications (2011)

- Part 2: Terms, definitions and surface texture parameters (2011)

- Part 3: Specification operators (2011)

- Part 4: Comparison rules

- Part 5: Verification operators

- Part 6: Classification of methods for measuring surface texture (2010)

- Part 70: Measurement standards for areal surface texture measurement instruments (2011)

- Part 71: Software measurement standards (2011)

- Part 72: Software measurement standards - XML file format (2011)

- Part 601: Nominal characteristics of contact (stylus) instruments (2010) 
- Part 602: Nominal characteristics of non-contact (confocal chromatic probe) instruments (2010)

- Part 603: Nominal characteristics of non-contact (phase shifting interferometric microscopy) instruments (2011)

- Part 604: Nominal characteristics of non-contact (coherence scanning interferometry) instruments (2011)

- Part 605: Nominal characteristics of non-contact (point autofocus) instruments (2011)

- Part 606: Nominal characteristics of non-contact (variable focus) instruments (2011)

- Part 607: Nominal characteristics of non-contact (imaging confocal) instruments (2011)

- Part 700: Calibration of non-contact instruments (2011)

- Part 701: Calibration and measurement standards for contact (stylus) instruments (2010)

At the time of writing, a general standard on the calibration of all areal surface topography measuring instruments is being drafted, but is not yet a committee draft. The American National Standards Institute has also published a comprehensive documentary specification standard, ANSI/ASME B46.1 (2010) that includes some areal analyses (mainly fractal based).

There are many different types of optical instruments that can measure surface texture. The techniques can be broken down into two major classes - those that measure the actual surface topography by either scanning a beam or using the field of view (profile or areal methods), and those that measure a statistical parameter of the surface, usually by analysing the distribution of scattered light (area integrating methods). There are many factors that need to be considered when choosing a method for measuring surface texture. Some of the questions that need to be addressed are as follows [9]:

- What type of surfaces do you need to measure?

This question may not have a straightforward answer; you may need to measure a single type of surface for a production process, or you may need a generic instrument to measure a whole range of surfaces. Further questions in this category include:

- What surface geometries need measuring? This includes the spatial frequency spectrum and the amplitude distribution.

- What surface materials do you need to measure? This includes the material hardness, optical characteristics, electrical characteristics and chemistry.

- What overall size of object do you need to measure the surface of?

Some instruments will have a limited size of object that can be placed on the measurement table, for example some optical instruments will have limited object height due to the finite stand-off of the objective lens. Modern instruments tend to have the ability to accommodate relatively large object sizes, but in the case of some older SPMs, the object needs to be less than $1 \mathrm{~mm}$ in height with a base area of a few square millimetres.

- How fast do you need the measurement to be?

This is an important consideration because the measurement times for the various instruments vary considerably. Optical methods tend to have shorter measurement times than stylus instruments, especially where areal measurements are required. The time to prepare the sample may also be important, for example, when using an SEM, it is necessary to apply a conducting coating to a dielectric sample and allow for time to pump the instrument down to the required level of vacuum.

- What sort of measurement uncertainty do you require?

The answer to this question will depend on such things as what sort of manufacturing 
tolerances you need to meet and what type of quality system you need to comply with. Uncertainty analysis is very complex for surface texture measurement but good practice should always be applied.

- What characterisation options do you require?

As with the first question, this question is often not simple to answer. It will depend on what types of surfaces need measuring, what types of process you are trying to control and what sort of quality system you need to comply with. In some cases just a single profile parameter may be required with default filter settings, but in another case, complex areal analysis may be required with multiple filtering options.

- What is your financial budget?

Surface texture measuring instruments can range from a few thousand euros for a simple hand-held stylus instrument to several hundred thousand euros for a high-end SPM or optical instrument with full product support and characterization software. Even when the questions above have indicated that an optical instrument is required, there are still many decisions to be made. It is one of the central aims of this book to help metrologists with these complicated choices. There is rarely an obvious frontrunner when considering the different optical techniques, so it will be useful to have a single source that can allow informed comparisons to be made.

There are a lot of factors affecting uncertainty in surface geometry measurement. They are caused by environment, measuring equipment, measured object, software and measuring method $[13,14,16]$. Parameters variations can be substantial source of the measurement uncertainty of surface topography. Variability of 2D profile parameters on typical manufactured surfaces was studied [15]. The authors of papers [5,6,12] analysed variations of areal (3D) parameters. Authors of works [7,12] studied variability of areal surface topography parameters. The main aim of this work was to study the effect of light intensity variation on change of surface topography parameters. The other aim was to select parameters of the smallest and highest sensitivity on light intensity.

\section{EXPERIMENTAL}

Several machined surface topographies with different values of texture aspect ratio Str were analysed. However 2 groups of textures were subjected to detailed study. They were ground (S1) and shot-peened (S2) surfaces. Measurements were made by white light interferometer Talysurf CCI Lite, version 2.8.2.95. Height resolution was $0.01 \mathrm{~nm}$, the measuring area was $3.3 \mathrm{~mm} \mathrm{x} 3.3 \mathrm{~mm}$ (lens 5). All surfaces were measured with different light intensity. Light intensity was changed in the range $10 \%-90 \%$ every time at $5 \%$. As a reference elements to compare changes of surface topography parameters were used surfaces with the smallest number of non-measured points. Producers of optical interferometers maintained that proper results of measurement one can get when the number of non-measured points is lower than 20$25 \%$. After measurement each surface was levelled and non-measured points were filled up. Digital filtration was not used. Parameters from ISO 25178 standard were calculated (Table 1). Parameters were calculated using the software Talymap Gold, version 6.0. All feature parameters were calculated after a discrimination by segmentation using a Wolfpruning of 5\% of the value of the $S z$ parameter (maximum height). For volume parameters calculation material ratio p was $10 \%, q$ was $80 \%$. Parameters from the $S k$ family (areal extension of ISO 13565-2 standard - see Table 1): $S k, S p k, S v k, S r l$ and $S r 2$ were also computed. Influence of light 
intensity on the change of surface topography parameters was analysed. Every measurement was repeated four times.

\section{DISCUSSION}

Table 2 presents number of non-measured points after surface topography measurement with different light intensity. Changes of surface topography parameters depending on changes of light intensity were presented in Tables 3-6. Figures 1-2 present ground and shot-peened surfaces which were used to the measurements. The Str texture parameter was used to describe the level of isotropy of a rough surface; a ratio of 1 indicates a perfectly isotropic surface topography. Strongly anisotropic one-directional ground surface $(S t r=0.0189)$ of normal ordinate distribution is characterized by the $S q$ parameter (standard deviation of height) of $0.308 \mu \mathrm{m}$ and the $\mathrm{Sal}$ parameter (the fastest decay auto-correlation length) of $0.0091 \mathrm{~mm}$.

Table 1. List of surface topography parameters (according to ISO 25178)

\begin{tabular}{|c|c|c|c|c|c|}
\hline Parameter & Unit & Description & Parameter & Unit & Description \\
\hline \multicolumn{2}{|c|}{ Height Parameters } & & \multicolumn{2}{|c|}{ Feature Parameters } & \\
\hline $\mathrm{Sq}$ & $\mu \mathrm{m}$ & Root mean square height & Spd & $1 / \mathrm{mm}^{2}$ & Density of peaks \\
\hline Ssk & & Skewness & Spc & $1 / \mathrm{mm}$ & $\begin{array}{l}\text { Arithmetic mean peak } \\
\text { curvature }\end{array}$ \\
\hline Sku & & Kurtosis & S10z & $\mu \mathrm{m}$ & Ten point height \\
\hline Sp & $\mu \mathrm{m}$ & Maximum peak height & S5p & $\mu \mathrm{m}$ & Five point peak height \\
\hline Sv & $\mu \mathrm{m}$ & Maximum pit height & S5v & $\mu \mathrm{m}$ & Five point pit height \\
\hline $\mathbf{S z}$ & $\mu \mathrm{m}$ & Maximum height & Sda & $\mathrm{mm}^{2}$ & Mean dale area \\
\hline Sa & $\mu \mathrm{m}$ & Arithmetic mean height & Sha & $\mathrm{mm}^{2}$ & Mean hill area \\
\hline \multicolumn{2}{|c|}{ Functional Parameters } & & Sdv & $\mathrm{mm}^{3}$ & Mean dale volume \\
\hline Smr & $\%$ & Areal material ratio & Shv & $\mathrm{mm}^{3}$ & Mean hill volume \\
\hline Smc & $\mu \mathrm{m}$ & Inverse areal material ratio & \multicolumn{2}{|c|}{ Sk parameters } & \\
\hline Sxp & $\mu \mathrm{m}$ & Extreme peak height & Sk & $\mu \mathrm{m}$ & Core depth \\
\hline \multicolumn{2}{|c|}{ Spatial Parameters } & & Spk & $\mu \mathrm{m}$ & Reduced summit height \\
\hline Sal & $\mathrm{mm}$ & Auto-correlation length & Svk & $\mu \mathrm{m}$ & Reduced valley depth \\
\hline Str & & Texture-aspect ratio & Sr1 & $\%$ & Material ratio of summits \\
\hline Std & $\circ$ & Texture direction & Sr2 & $\%$ & Material ratio of valleys \\
\hline \multicolumn{2}{|c|}{$\begin{array}{c}\text { Functional Parameters } \\
\text { (volume) }\end{array}$} & & \multicolumn{2}{|c|}{ Hybrid Parameters } & \\
\hline Vm & $\mathrm{mm}^{3} / \mathrm{mm}^{2}$ & Material volume & Sdq & & $\begin{array}{l}\text { Root mean square } \\
\text { gradient }\end{array}$ \\
\hline $\mathbf{V v}$ & $\mathrm{mm}^{3} / \mathrm{mm}^{2}$ & Void volume & Sdr & $\%$ & $\begin{array}{c}\text { Developed interfacial } \\
\text { area ratio }\end{array}$ \\
\hline Vmp & $\mathrm{mm}^{3} / \mathrm{mm}^{2}$ & Peak material volume & & & \\
\hline Vmc & $\mathrm{mm}^{3} / \mathrm{mm}^{2}$ & Core material volume & & & \\
\hline Vve & $\mathrm{mm}^{3} / \mathrm{mm}^{2}$ & Core void volume & & & \\
\hline Vvv & $\mathrm{mm}^{3} / \mathrm{mm}^{2}$ & Pit void volume & & & \\
\hline
\end{tabular}


Table 2. Number of non-measured points (in \%) after surface topography measurement with different light intensity

\begin{tabular}{|c|c|c|c|c|c|c|}
\hline Light intensity [\%] & $\mathbf{1 0}$ & $\mathbf{1 5}$ & $\mathbf{2 0}$ & $\mathbf{2 5}$ & $\mathbf{3 0}$ & $\mathbf{3 5}$ \\
\hline Grinding & $20.5 \%$ & $4.81 \%$ & $1.14 \%$ & $0.35 \%$ & $0.2 \%$ & $0.063 \%$ \\
\hline Shot-peening & $83.6 \%$ & $\mathbf{6 4 . 6} \%$ & $50.5 \%$ & $38.1 \%$ & $28.3 \%$ & $21.2 \%$ \\
\hline Light intensity [\%] & $\mathbf{4 0}$ & $\mathbf{4 5}$ & $\mathbf{5 0}$ & $\mathbf{5 5}$ & $\mathbf{6 0}$ & $\mathbf{6 5}$ \\
\hline Grinding & $0.033 \%$ & $0.013 \%$ & $\mathbf{0 . 0 0 7 \%}$ & $0.015 \%$ & $0.076 \%$ & $0.492 \%$ \\
\hline Shot-peening & $15.6 \%$ & $10.6 \%$ & $7.67 \%$ & $5.51 \%$ & $4.1 \%$ & $2.69 \%$ \\
\hline Light intensity [\%] & $\mathbf{7 0}$ & $\mathbf{7 5}$ & $\mathbf{8 0}$ & $\mathbf{8 5}$ & $\mathbf{9 0}$ & \\
\hline Grinding & $2.25 \%$ & $8.02 \%$ & $17.6 \%$ & $38.9 \%$ & $60.3 \%$ & \\
\hline Shot-peening & $3.11 \%$ & $4.31 \%$ & $7.25 \%$ & $13.8 \%$ & $28.3 \%$ \\
\hline
\end{tabular}

a)

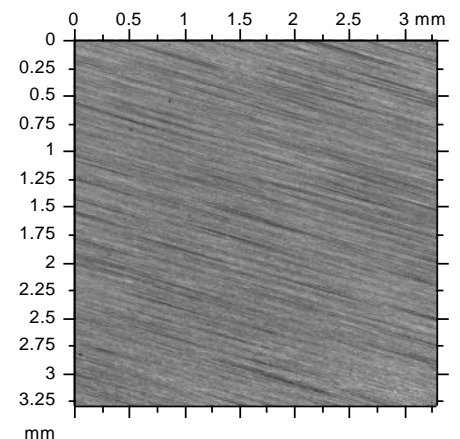

b)

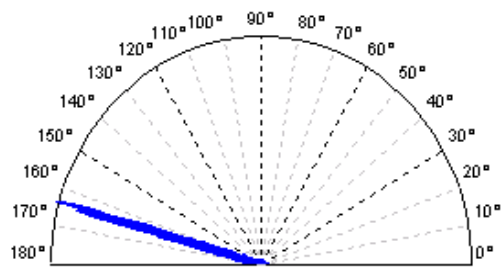

Isotropy: $1.89 \%$

Finst Direction: $164^{\circ}$

Second Direction: $158^{\circ}$

Third Direction: $170^{\circ}$

c)

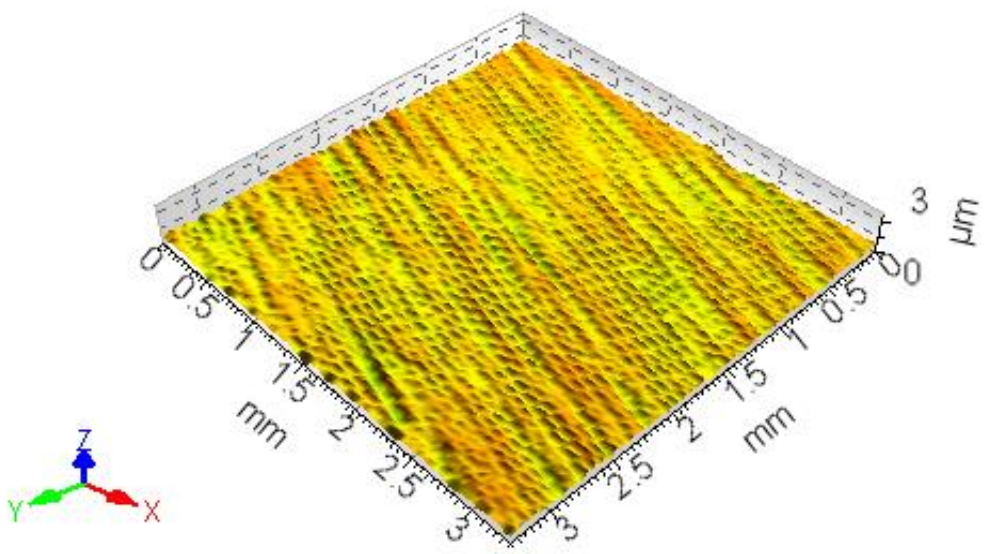

Figure 1. Ground surface (S1): a) surface photography, b) texture direction,

c) isometric view 
The smallest number of non-measured points of ground surface was obtained in the case of $50 \%$ of light intensity. It was only $0.007 \%$. Good results we obtained in wide range of light intensity. Between 15 and $75 \%$ number of non-measured points of anisotropic surface was smaller than $10 \%$.

Different situation we achieved in the case of shot-peened surface. Shot-peened surface is strongly isotropic surface with $\mathrm{Str}=0.907$. The smallest number of non-measured points of shot-peened surface was obtained in the case of $65 \%$ of light intensity. It was $2.69 \%$. The range of low level of non-measured points was narrower than in ground surface. This range, lower than $10 \%$ was observed between $45-80 \%$.

a)

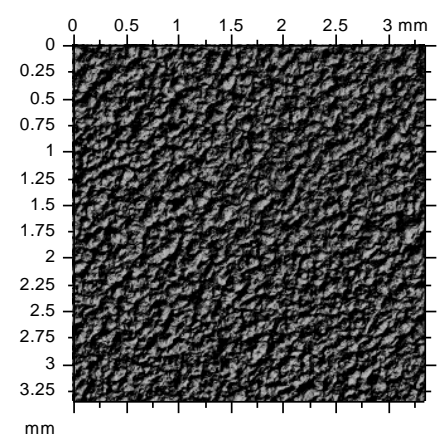

b)

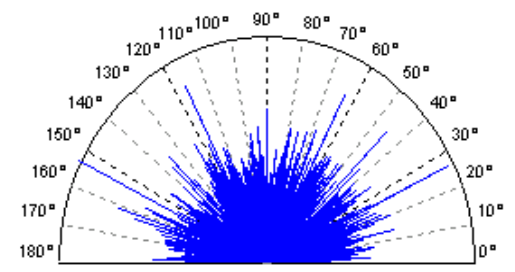

Isotropy: $90.7 \%$

First Direction: $154^{\circ}$

Second Direction: $26.5^{\circ}$

Third Direction: $116^{\circ}$

c)

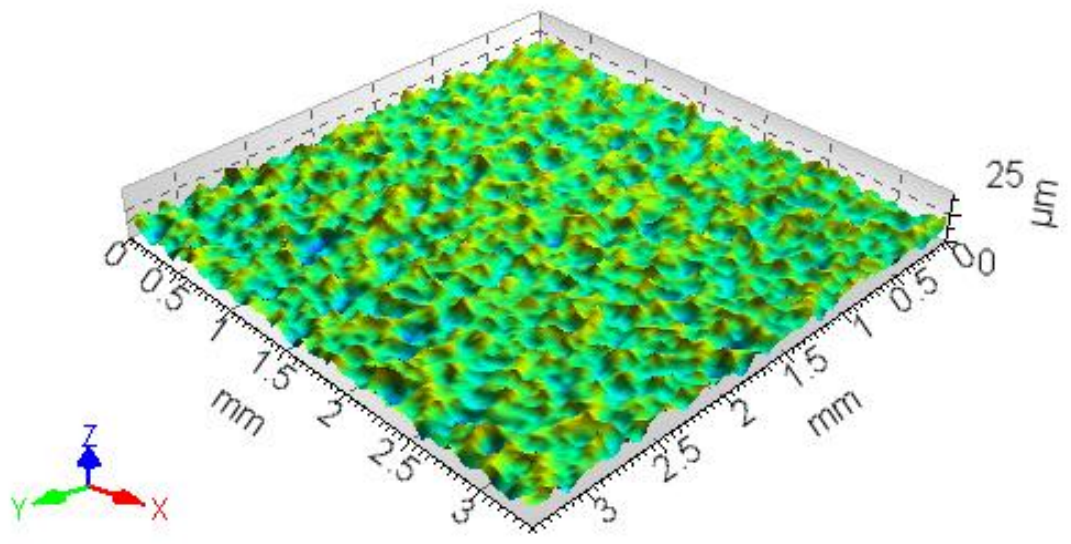

Figure 2. Shot-peened surface (S2): a) surface photography, b) texture direction, c) isometric view

To compare changes of surface topography parameters were used surfaces with the smallest number of non-measured points. It was surface with $50 \%$ of light intensity in the case of ground surface and with $65 \%$ of light intensity in the case of shot-peened surface. Changes of amplitude parameters of surface S1 were small (below 10\%) when light intensity contained in the range $20-70 \%$. When light intensity was smaller than $20 \%$ and larger than $70 \%$ one can observe 
gradual increase parameters like $S s k$ and $S p$. Several parameters like $S q$, $S a, S k u$ behaved stably even though number of non-measured points was significant (above 20-30\%). In the group of spatial parameters is clearly visible the change of $\mathrm{Smr}$ parameter. Changes of this parameter achieved $100 \%$. Changes of light intensity didn't cause significant difference of hybrid parameters, although number of non-measured points in several cases was large. Similar situation was observed with spatial parameter. When the number of non-measured points was smaller than $10 \%$ functional parameters behaved stably and changes of those parameters didn't exceed $10 \%$. Changes of feature parameters due to change of light intensity were visible in several cases, specially $S 5 v$ and $S d v$. In the range of number of non-measured points below $10 \%$ changes both mentioned parameter achieved 20\%. Parameters from $S k$ family were not sensitive on change of light intensity when number of non-measured points was smaller than $10 \%$.

Contrary to ground surface, height parameters of surface S2 were not as stable as on the surface $\mathrm{S} 1$. When the number of non-measured points was smaller than $10 \%$ (it was between 45 and $80 \%$ of light intensity) variability of parameters like $S v$ or $S z$ achieved $40-50 \%$. Average parameters like $S a, S q$ were stable in the whole range. Similarly to the surface $S 1$ functional parameter Smr was also not stable, changes of this parameter was larger than $100 \%$. Spatial, hybrid and functional (volume) parameters behaved stably in the range $45-80 \%$ of light intensity, that equals number of non-measured points below $10 \%$.

Several feature parameters didn't behave stably in the case of change of light intensity. Such situation took place specially with $S d a, S h a, S d v$ parameters. Variability of those parameters achieved $40 \%$. Parameters from $S k$ family were not sensitive on change of light intensity when number of non-measured points was smaller than $10 \%$.

Surface topography is characterized through the use of parameters of different stability. Average parameters like $S a, S q$ are supposed to be stable on surface, contrary to parameters related to maximum amplitude, like $S p, S v$. It is widely known that skewness $S s k$ and kurtosis $S k u$ are sensitive to spiky features $[5,6,15]$.

Hybrid parameters are sensitive to the sampling interval [11], which was constant in this study. It is evident that the variability of the Smr parameter is the biggest. Therefore method of calculation of Smr ought to be changed. This parameter was calculated by software TalyMap at a distance $c$ of $1 \mathrm{~mm}$ from the highest peak. Smaller variability of this parameter should be obtained when this specified height $\mathrm{c}$ was calculated from the surface mean plane. 
Table 3. Changes of surface topography parameters depending on changes of light intensity (ground surface); gray column - parameter values; other columns - changes of surface parameters (in \%)

\begin{tabular}{|c|c|c|c|c|c|c|c|c|c|}
\hline \multirow{2}{*}{ Parameter } & \multicolumn{9}{|c|}{ Light intensity [\%] } \\
\hline & 50 & 45 & 40 & 35 & 30 & 25 & 20 & 15 & 10 \\
\hline$S q$ & 0.308 & 0 & 0.65 & 0.97 & 2.27 & 2.60 & 4.22 & 6.82 & 11.69 \\
\hline Ssk & -0.433 & 1.62 & 1.15 & 1.15 & 4.62 & 5.31 & 9.24 & 11.32 & 18.48 \\
\hline Sku & 3.85 & 0.78 & 0.52 & 0.78 & 0.52 & 0.52 & 0 & 0.52 & 3.64 \\
\hline$S p$ & 1.43 & 3.50 & 6.29 & 1.40 & 9.79 & 3.50 & 9.79 & 16.08 & 15.38 \\
\hline Sv & 2.36 & 2.12 & 4.66 & 2.54 & 4.24 & 2.12 & 7.20 & 18.64 & 16.10 \\
\hline$S z$ & 3.8 & 0.26 & 0.26 & 0.53 & 1.32 & 0 & 0.79 & 17.89 & 16.32 \\
\hline$S a$ & 0.239 & 0.00 & 0.84 & 0.84 & 2.09 & 2.51 & 3.77 & 6.28 & 11.72 \\
\hline Smr & 6.6 & 41.52 & 83.33 & 16.36 & 146.97 & 33.94 & 128.79 & $84.1 /$ & 98.6 \\
\hline Smc & 1.06 & 4.72 & 8.40 & 1.89 & 13.02 & 3.77 & 11.70 & 27.21 & 23.85 \\
\hline Sxp & 0.694 & 0.43 & 0.86 & 1.30 & 2.45 & 2.74 & 4.18 & 19.62 & 17.08 \\
\hline Sal & 0.0091 & 0 & 0 & 0 & 0 & 0 & 0 & 6.92 & 11.82 \\
\hline Str & 0.0189 & 0 & 0 & 1.59 & 2.12 & 2.65 & 4.76 & 5.51 & 9.11 \\
\hline Std & 164 & 0 & 0 & 0 & 0 & 0 & 0 & 6.15 & 12.09 \\
\hline$S d q$ & 0.0883 & 0.57 & 2.38 & 3.51 & 6.91 & 8.27 & 12.46 & 1.59 & 1.59 \\
\hline$S d r$ & 0.389 & 1.29 & 4.88 & 6.94 & 13.37 & 15.94 & 23.39 & 0 & 0 \\
\hline$V m$ & $1.30 \mathrm{E}-05$ & 0 & 1.54 & 2.31 & 4.62 & 6.15 & 9.23 & 10.15 & 15.14 \\
\hline$V v$ & 0.000384 & 0 & 0.78 & 0.78 & 2.08 & 2.34 & 3.65 & 9.03 & 32.16 \\
\hline$V m p$ & $1.30 \mathrm{E}-05$ & 0 & 1.54 & 2.31 & 4.62 & 6.15 & 9.23 & 9.45 & 53.98 \\
\hline$V m c$ & 0.000264 & 0 & 0.76 & 0.76 & 2.27 & 2.27 & 3.79 & 4.52 & 6.89 \\
\hline$V v c$ & 0.000341 & 0.29 & 0.59 & 0.59 & 2.05 & 2.05 & 3.52 & 10.54 & 16.92 \\
\hline$V v v$ & $4.28 \mathrm{E}-05$ & 0.47 & 0.93 & 1.17 & 2.34 & 3.04 & 4.21 & 6.25 & 11.20 \\
\hline Spd & 1457 & 0.89 & 4.67 & 8.17 & 12.83 & 17.09 & 27.18 & 11.54 & 16.92 \\
\hline$S p c$ & 0.0648 & 1.23 & 4.01 & 5.86 & 11.27 & 13.73 & 19.14 & 6.06 & 11.36 \\
\hline S10z & 2.57 & 6.23 & 8.17 & 3.89 & 14.79 & 6.23 & 14.79 & 6.16 & 11.14 \\
\hline$S 5 p$ & 0.999 & 3.80 & 4.50 & 1.70 & 8.11 & 4.40 & 2.70 & 7.01 & 11.68 \\
\hline S5v & 1.57 & 7.64 & 10.19 & 5.10 & 19.11 & 7.64 & 22.93 & 24.96 & 29.47 \\
\hline Sda & 0.00387 & 2.07 & 8.53 & 0.52 & 14.99 & 17.05 & 27.13 & 17.91 & 45.78 \\
\hline Sha & 0.00877 & 1.60 & 6.96 & 8.89 & 8.55 & 27.71 & 27.71 & 31.48 & 43.52 \\
\hline$S d v$ & $1.04 \mathrm{E}-08$ & 1.92 & 11.54 & 6.73 & 14.42 & 16.35 & 26.92 & 22.96 & 24.12 \\
\hline Shv & $2.48 \mathrm{E}-08$ & 4.03 & 3.63 & 12.50 & 6.05 & 23.79 & 27.42 & 14.91 & 19.12 \\
\hline$S k$ & 0.752 & 0.27 & 1.20 & 0.93 & 2.79 & 2.66 & 4.26 & 28.03 & 26.75 \\
\hline Spk & 0.25 & 1.20 & 2.00 & 2.00 & 4.00 & 6.00 & 8.80 & 14.99 & 59.43 \\
\hline Svk & 0.427 & 0.70 & 0.47 & 0.94 & 2.11 & 2.58 & 3.04 & 25.43 & 44.10 \\
\hline Sr1 & 8.4 & 2.38 & 0.83 & 1.55 & 2.86 & 1.90 & 3.45 & 5.77 & 31.73 \\
\hline $\mathrm{Sr} 2$ & 88.3 & 0 & 0 & 0.11 & 0 & 0.11 & 0.11 & 10.08 & 85.48 \\
\hline
\end{tabular}


Table 4. Changes of surface topography parameters depending on changes of light intensity (ground surface); gray column - parameter values; other columns - changes of surface parameters (in \%)

\begin{tabular}{|c|c|c|c|c|c|c|c|c|c|}
\hline \multirow{2}{*}{ Parameter } & \multicolumn{9}{|c|}{ Light intensity [\%] } \\
\hline & 50 & 55 & 60 & 65 & 70 & 75 & 80 & 85 & 90 \\
\hline$S q$ & 0.308 & 0.32 & 0.65 & 1.30 & 1.95 & 3.90 & 5.19 & 5.84 & 2.92 \\
\hline Ssk & -0.433 & 3.00 & 2.31 & 4.85 & 8.78 & 15.70 & 21.02 & 33.26 & 45.96 \\
\hline Sku & 3.85 & 0.52 & 0.26 & 0.26 & 0.52 & 0.52 & 0.26 & 4.68 & 8.83 \\
\hline$S p$ & 1.43 & 1.40 & 1.40 & 6.99 & 5.59 & 11.19 & 14.69 & 39.16 & 55.24 \\
\hline$S v$ & 2.36 & 0 & 4.66 & 5.08 & 3.39 & 2.97 & 1.69 & 5.51 & 10.59 \\
\hline $\mathrm{Sz}$ & 3.8 & 0.53 & 2.11 & 5.53 & 3.95 & 5.79 & 6.32 & 17.89 & 27.11 \\
\hline$S a$ & 0.239 & 0.42 & 0.84 & 1.26 & 2.09 & 3.77 & 4.60 & 4.60 & 1.26 \\
\hline$S m r$ & 6.6 & 13.79 & 15.00 & 47.88 & 40.91 & 63.18 & 71.67 & 96.61 & 99.30 \\
\hline Smc & 1.06 & 1.89 & 1.89 & 8.49 & 7.55 & 14.15 & 17.92 & 50.00 & 53.58 \\
\hline Sxp & 0.694 & 0 & 0.58 & 0.72 & 1.30 & 2.74 & 3.46 & 3.03 & 1.44 \\
\hline Sal & 0.0091 & 0 & 0 & 20.88 & 20.88 & 20.88 & 0 & 12.09 & 90.11 \\
\hline Str & 0.0189 & 0.53 & 0.53 & 18.52 & 17.99 & 15.87 & 11.64 & 26.51 & 28.78 \\
\hline Std & 164 & 0 & 0 & 0 & 0 & 0 & 0 & 0 & 0.61 \\
\hline$S d q$ & 0.0883 & 0.91 & 1.59 & 2.49 & 3.51 & 5.78 & 5.78 & 0.57 & 13.14 \\
\hline$S d r$ & 0.389 & 1.54 & 2.83 & 4.88 & 6.94 & 11.57 & 11.57 & 1.03 & 24.68 \\
\hline$V m$ & $1.30 \mathrm{E}-05$ & 1.54 & 2.31 & 3.08 & 5.38 & 10.00 & 14.62 & 23.08 & 26.92 \\
\hline$V v$ & 0.000384 & 0.26 & 0.52 & 1.30 & 2.08 & 4.17 & 5.21 & 6.51 & 3.91 \\
\hline$V m p$ & $1.30 \mathrm{E}-05$ & 1.54 & 2.31 & 3.08 & 5.38 & 10.00 & 14.62 & 23.08 & 26.92 \\
\hline$V m c$ & 0.000264 & 0 & 0.38 & 0.76 & 1.52 & 3.41 & 4.17 & 3.03 & 1.89 \\
\hline$V v c$ & 0.000341 & 0.59 & 0.59 & 1.17 & 2.35 & 4.40 & 5.57 & 6.74 & 4.40 \\
\hline$V v v$ & $4.28 \mathrm{E}-05$ & 0 & 0.70 & 0.70 & 1.17 & 2.57 & 3.50 & 4.44 & 0.93 \\
\hline Spd & 1457 & 1.72 & 1.30 & 0.34 & 3.36 & 6.18 & 5.42 & 11.53 & 35.96 \\
\hline$S p c$ & 0.0648 & 1.85 & 2.62 & 4.17 & 3.24 & 4.17 & 4.17 & 7.25 & 7.41 \\
\hline S10z & 2.57 & 3.89 & 12.45 & 11.67 & 8.17 & 7.78 & 11.28 & 16.34 & 30.74 \\
\hline$S 5 p$ & 0.999 & 1.10 & 1.90 & 0.30 & 12.11 & 24.12 & 36.14 & 43.14 & 47.15 \\
\hline$S 5 v$ & 1.57 & 6.37 & 19.11 & 19.11 & 21.02 & 2.55 & 4.46 & 1.27 & 21.02 \\
\hline$S d a$ & 0.00387 & 0.26 & 0.78 & 4.39 & 6.20 & 0.52 & 11.37 & 44.70 & 118.09 \\
\hline Sha & 0.00877 & 0.91 & 2.62 & 4.10 & 3.99 & 7.18 & 5.13 & 3.76 & 2.96 \\
\hline$S d v$ & $1.04 \mathrm{E}-08$ & 3.85 & 7.69 & 13.46 & 15.38 & 14.42 & 36.54 & 69.23 & 145.19 \\
\hline Shv & $2.48 \mathrm{E}-08$ & 0.40 & 2.02 & 7.66 & 5.24 & 1.61 & 9.27 & 26.61 & 48.39 \\
\hline$S k$ & 0.752 & 1.06 & 0.40 & 0.13 & 0.93 & 3.32 & 3.72 & 1.20 & 3.59 \\
\hline Spk & 0.25 & 1.20 & 2.00 & 3.20 & 7.60 & 10.80 & 14.80 & 26.00 & 32.00 \\
\hline Svk & 0.427 & 0.70 & 0.70 & 0.94 & 2.34 & 1.17 & 2.58 & 5.39 & 1.87 \\
\hline Sr1 & 8.4 & 5.60 & 5.71 & 5.60 & 3.69 & 3.45 & 6.79 & 16.43 & 25.00 \\
\hline $\mathrm{Sr} 2$ & 88.3 & 0 & 0 & 0 & 0.11 & 0.00 & 0 & 0.11 & 0 \\
\hline
\end{tabular}


Table 5. Changes of surface topography parameters depending on changes of light intensity (shot-peened surface); gray column - parameter values; other columns - changes of surface parameters (in \%)

\begin{tabular}{|c|c|c|c|c|c|c|c|c|c|}
\hline \multirow[b]{2}{*}{ Parameter } & \multicolumn{9}{|c|}{ Light intensity [\%] } \\
\hline & 65 & 70 & 75 & 80 & 85 & 90 & 60 & 55 & 50 \\
\hline$S q$ & 2.42 & 0 & 0 & 0 & 0.41 & 2.07 & 0 & 0 & 0.41 \\
\hline Ssk & 0.0634 & 5.52 & 5.21 & 7.41 & 4.73 & 1.42 & 1.26 & 0.47 & 3.47 \\
\hline Sku & 3.17 & 0.32 & 0.95 & 1.26 & 2.84 & 6.62 & 0 & 0.32 & 0 \\
\hline$S p$ & 15.5 & 14.84 & 14.19 & 3.87 & 5.16 & 7.10 & 18.71 & 29.68 & 5.81 \\
\hline$S v$ & 11.1 & 61.26 & 47.75 & 49.55 & 77.48 & 51.35 & 39.64 & 6.31 & 9.91 \\
\hline$S z$ & 26.6 & 34.21 & 28.20 & 18.42 & 35.34 & 25.94 & 27.44 & 20.30 & 7.52 \\
\hline$S a$ & 1.92 & 0 & 0 & 0.52 & 0.52 & 3.12 & 0 & 0 & 0 \\
\hline Smr & $9.54 \mathrm{E}-05$ & 0 & 0 & 278.41 & 199.79 & 100.21 & 0 & 69.95 & 92.11 \\
\hline Smc & 12.3 & 18.70 & 18.70 & 4.07 & 7.32 & 10.57 & 24.39 & 6419.92 & 0 \\
\hline Sxp & 4.65 & 0 & 0 & 0 & 0.22 & 1.51 & 0 & 37.07 & 7.32 \\
\hline Sal & 0.0508 & 0 & 0 & 0 & 0 & 1.77 & 0 & 0 & 0.22 \\
\hline Str & 0.907 & 0 & 0 & 0 & 0 & 0.22 & 0 & 0 & 0.52 \\
\hline Std & 154 & 0 & 0 & 0 & 0 & 0 & 0 & 0 & 0 \\
\hline$S d q$ & 0.18 & 2.22 & 5.00 & 7.22 & 11.67 & 12.22 & 2.22 & 0 & 0 \\
\hline$S d r$ & 1.58 & 3.80 & 8.86 & 13.29 & 21.52 & 21.52 & 3.16 & 0 & 0 \\
\hline$V m$ & 0.000123 & 0.81 & 0 & 0.81 & 0 & 0.81 & 0 & 0.81 & 0 \\
\hline$V v$ & 0.00324 & 0 & 0 & 0 & 0.31 & 2.47 & 0.31 & 2.22 & 2.22 \\
\hline$V m p$ & 0.000123 & 0.81 & 0 & 0.81 & 0 & 0.81 & 0 & 3.80 & 3.80 \\
\hline$V m c$ & 0.00214 & 0.47 & 0.47 & 0.47 & 0.93 & 3.74 & 0.47 & 2.11 & 6.02 \\
\hline$V v c$ & 0.00297 & 0 & 0 & 0 & 0.34 & 2.69 & 0 & 0 & 0 \\
\hline$V v v$ & 0.00027 & 0.37 & 0.37 & 0 & 0 & 0.37 & 0.37 & 0 & 0.31 \\
\hline Spd & 69.4 & 16.57 & 11.24 & 3.03 & 2.88 & 10.23 & 21.33 & 0 & 0 \\
\hline Spc & 0.141 & 42.55 & 68.79 & 96.45 & 149.65 & 174.47 & 33.62 & 0 & 0 \\
\hline$S 10 z$ & 24.8 & 8.47 & 14.11 & 12.90 & 18.55 & 20.16 & 17.74 & 0 & 0.34 \\
\hline$S 5 p$ & 12.6 & 3.17 & 11.11 & 7.14 & 9.52 & 18.25 & 13.49 & 0.37 & 0 \\
\hline S5v & 12.2 & 13.93 & 17.21 & 18.85 & 27.87 & 22.13 & 21.89 & 24.68 & 29.35 \\
\hline$S d a$ & 0.118 & 42.37 & 26.27 & 20.34 & 0.85 & 17.46 & 47.46 & 14.99 & 2.02 \\
\hline Sha & 0.121 & 26.45 & 19.83 & 10.74 & 22.31 & 14.88 & 21.49 & 15.70 & 9.92 \\
\hline$S d v$ & $6.34 \mathrm{E}-06$ & 45.27 & 18.14 & 9.31 & 12.30 & 22.56 & 54.57 & 26.34 & 5.68 \\
\hline Shv & 4.37E-06 & 20.14 & 16.02 & 7.78 & 18.54 & 3.89 & 27.00 & 21.51 & 15.56 \\
\hline$S k$ & 6.19 & 0.16 & 0.81 & 0.81 & 1.13 & 3.72 & 0.32 & 0.48 & 0.65 \\
\hline Spk & 2.43 & 0.41 & 0.41 & 0.41 & 0.41 & 0.82 & 1.23 & 2.06 & 0.82 \\
\hline Svk & 2.38 & 5.88 & 5.46 & 6.72 & 9.66 & 6.30 & 5.04 & 0 & 0.42 \\
\hline Sr1 & 10.3 & 0.97 & 0.97 & 1.94 & 0 & 0.97 & 0.97 & 1.94 & 2.91 \\
\hline$S r 2$ & 90.6 & 0 & 0.11 & 0 & 0.11 & 0.33 & 0 & 0.11 & 0 \\
\hline
\end{tabular}


Table 6. Changes of surface topography parameters depending on changes of light intensity (shot-peened surface); gray column - parameter values; other columns - changes of surface parameters (in \%)

\begin{tabular}{|c|c|c|c|c|c|c|c|c|c|}
\hline \multirow{2}{*}{ Parameter } & \multicolumn{9}{|c|}{ Light intensity [\%] } \\
\hline & 65 & 45 & 40 & 35 & 30 & 25 & 20 & 15 & 10 \\
\hline$S q$ & 2.42 & 0.41 & 0.41 & 0.41 & 0.41 & 0.41 & 0 & 2.07 & 7.02 \\
\hline Ssk & 0.0634 & 1.26 & 4.42 & 10.41 & 20.50 & 44.32 & 72.87 & 119.24 & 179.65 \\
\hline Sku & 3.17 & 0.32 & 0.32 & 0.63 & 0.63 & 0.95 & 0.32 & 0.63 & 5.36 \\
\hline$S p$ & 15.5 & 29.68 & 30.97 & 30.32 & 29.68 & 31.61 & 30.97 & 30.32 & 29.68 \\
\hline$S v$ & 11.1 & 9.01 & 9.01 & 9.01 & 9.01 & 9.01 & 9.01 & 10.00 & 11.71 \\
\hline$S z$ & 26.6 & 21.05 & 21.80 & 21.43 & 21.05 & 22.18 & 21.80 & 22.18 & 22.18 \\
\hline$S a$ & 1.92 & 0 & 0 & 0.52 & 0.52 & 0.52 & 0.52 & 2.08 & 7.81 \\
\hline$S m r$ & $9.54 \mathrm{E}-05$ & 6461.84 & 8422.01 & 8495.39 & 7562.47 & 7027.88 & 6692.45 & 6839.20 & 8474.42 \\
\hline Smc & 12.3 & 36.75 & 38.29 & 37.80 & 37.15 & 39.02 & 38.05 & 37.07 & 34.47 \\
\hline Sxp & 4.65 & 0 & 0.22 & 0.43 & 0.65 & 1.08 & 1.29 & 0.43 & 2.80 \\
\hline Sal & 0.0508 & 0 & 0 & 0 & 0 & 0 & 0.59 & 3.35 & 7.87 \\
\hline Str & 0.907 & 0 & 0 & 0 & 0 & 0 & 0.22 & 0.99 & 0.22 \\
\hline Std & 154 & 0 & 0 & 0 & 0 & 0 & 0 & 0 & 0 \\
\hline$S d q$ & 0.18 & 2.22 & 2.22 & 2.22 & 3.33 & 5.00 & 8.89 & 15.56 & 29.44 \\
\hline$S d r$ & 1.58 & 3.80 & 3.16 & 4.43 & 5.70 & 9.49 & 16.46 & 27.85 & 49.49 \\
\hline$V m$ & 0.000123 & 0 & 0 & 0 & 0 & 1.63 & 2.44 & 4.88 & 7.32 \\
\hline$V v$ & 0.00324 & 0.31 & 0.31 & 0.31 & 0.62 & 0.31 & 0.93 & 3.09 & 9.88 \\
\hline$V m p$ & 0.000123 & 0 & 0 & 0 & 0 & 1.63 & 2.44 & 4.88 & 7.32 \\
\hline$V m c$ & 0.00214 & 0 & 0 & 0.47 & 0.47 & 0.47 & 0 & 1.87 & 8.41 \\
\hline$V v c$ & 0.00297 & 0.34 & 0.34 & 0.34 & 0.34 & 0.34 & 1.01 & 3.70 & 10.77 \\
\hline$V v v$ & 0.00027 & 0 & 0.37 & 0.37 & 0.74 & 0.74 & 1.11 & 1.11 & 0.37 \\
\hline Spd & 69.4 & 14.41 & 16.43 & 13.98 & 11.38 & 12.39 & 9.08 & 0.86 & 15.13 \\
\hline$S p c$ & 0.141 & 47.45 & 50.35 & 54.96 & 58.72 & 64.61 & 71.99 & 78.30 & 85.89 \\
\hline$S 10 z$ & 24.8 & 33.87 & 33.87 & 35.89 & 34.68 & 38.31 & 36.29 & 37.10 & 37.90 \\
\hline$S 5 p$ & 12.6 & 34.13 & 34.68 & 37.78 & 35.79 & 43.10 & 39.44 & 41.59 & 41.59 \\
\hline$S 5 v$ & 12.2 & 33.44 & 33.28 & 33.52 & 33.44 & 33.69 & 33.36 & 32.62 & 34.02 \\
\hline$S d a$ & 0.118 & 9.32 & 11.02 & 1.69 & 3.39 & 7.63 & 6.78 & 17.80 & 23.73 \\
\hline Sha & 0.121 & 16.53 & 16.53 & 14.88 & 13.22 & 12.40 & 6.61 & 2.48 & 28.10 \\
\hline$S d v$ & $6.34 \mathrm{E}-06$ & 23.66 & 12.30 & 3.79 & 12.15 & 35.96 & 7.10 & 0.63 & 10.09 \\
\hline Shv & $4.37 \mathrm{E}-06$ & 24.49 & 27.00 & 24.94 & 16.93 & 14.87 & 9.15 & 3.66 & 59.04 \\
\hline$S k$ & 6.19 & 0.16 & 0.65 & 0.16 & 0.81 & 0.32 & 0.32 & 1.78 & 8.89 \\
\hline$S p k$ & 2.43 & 1.65 & 0.00 & 1.23 & 0.41 & 0.82 & 1.65 & 5.35 & 7.41 \\
\hline$S v k$ & 2.38 & 0.84 & 0.42 & 0.42 & 1.26 & 0.84 & 2.10 & 1.26 & 0.42 \\
\hline Sr1 & 10.3 & 0.97 & 0.97 & 0.97 & 0.97 & 0.00 & 0.97 & 3.79 & 5.53 \\
\hline$S r 2$ & 90.6 & 0.11 & 0.00 & 0.11 & 0.11 & 0.00 & 0.00 & 0.22 & 0.99 \\
\hline
\end{tabular}




\section{CONCLUSIONS}

In recent years optical free-contact techniques for three-dimensional surface metrology have become increasingly important in contrast to traditional tactile measurement methods. All types of surfaces which may be polished or rough. curved. flat or stepped with reflectivity between $0.3 \%$ to $100 \%$ can be measured using optical interferometers.

Light intensity was changed from 10 to $90 \%$ in presented study. In the case of anisotropic surface. number of non-measured points due to light intensity changes was below $10 \%$ in the wide range $15-75 \%$. In the case of isotropic surface. that range was smaller: $45-80 \%$ respectively. In addition. anisotropic surface had number of non-measured points below $1 \%$ in the range of $25-65 \%$. That situation didn't occur with shot-peened surface. In the best variant of isotropic surface (65\% of light intensity) number of non-measured points amounted to $2.69 \%$.

The functional parameter Smr is the most sensitive to light intensity even if number of nonmeasured points was smaller than $10 \%$. The method of this parameter calculation should be changed. The feature parameters. particularly $S d a$. Sha. $S d v$ are also sensitive on light intensity changes. Average amplitude parameters like $S a$ and $S q$ were stable in the whole range of light intensity. Similarly to $S a$ and $S q$ parameters. spatial and hybrid parameters behaved stably when changes of those parameters didn't exceed $10 \%$.

\section{LITERATURE}

[1] BLUNT L.A.. JIANG. X.. Advanced techniques for assessment surface topography. Kogan Page Science. 2003.

[2] BRENNAN J. K.. Algorithms for surface texture profiles and parameters. Doctoral thesis. University of Huddersfield. 2010.

[3] BRUZZONE A.A.G.. COSTA H.L.. LONARDO P.M.. LUCCA D.A.. Advances in engineered surfaces for functional performance. W: Ann. CIRP 57. 2008. 750-769.

[4] De CHIFFRE L.. KUNZMANN H.. PEGGS G.N.. LUCCA D.A.. Surfaces in precision engineering. microengineering and nanotechnology. W: Ann. CIRP 52. 2003. 561-577.

[5] DONG W.P.. MAINSAH E.. STOUT K.J.. Comprehensive study of parameters for characterizing threedimensional surface topography. I: Statistical properties of parameters variations. W: Wear. vol. 159. 1992. 161171.

[6] DONG W.P.. MAINSAH E.. STOUT K.J.. Comprehensive study of parameters for characterizing threedimensional surface topography. II: Statistical properties of parameters variations. W: Wear. vol. 159. 1992. 161-171.

[7] DZIERWA A.. REIZER R.. PAWLUS P.. GRABON W.. Variability of areal surface topography parameters due to the change in surface orientation to measurement direction. W: Scanning vol. 36. 2014. 170-183.

[8] EVANS C.J.. BRYAN J.B.. "Structured”. "textured”. "engineered” surfaces. W: Ann. CIRP 48. 1999. 541556.

[9] LEACH R.. Optical Measurement of Surface Topography. Springer. Heidelberg. 2011.

[10] LONARDO P.M.. LUCCA D.A. De CHIFFRE L.E.. Emerging trends in surface metrology. W: Ann. CIRP 51. 2002. 701-723.

[11] PAWLUS P.. Digitisation of surface topography measurement results. Measurement vol. 40. 2007. $672-686$.

[12] PAWLUS P.. GRABON W.. REIZER R.. Variation of areal parameters on machined surfaces. 11th International Symposium on Measurement and Quality Control 2013. Cracow-Kielce. Poland.

[13] STOUT K.J. (ed). Three-dimensional surface topography - measurement. interpretation and application. Penton Press. London 1994.

[14] THOMAS T.R.. Rough Surfaces. Second Edition. Imperial College Press. London 1999.

[15] THOMAS T.R.. CHARLTON G.. Variation of roughness parameters on some typical manufactured surfaces. Precision Engineering. vol. 3(2). 1981. 91-96.

[16] WHITEHOUSE D.J.. Surfaces and Their Measurement. Hermes Penton. London. 2001. 